\title{
ANALISIS KADAR TOKOFEROL, $\gamma$-ORYZANOL DAN B-KAROTEN SERTA AKTIVITAS ANTIOKSIDAN MINYAK BEKATUL KASAR
}

\author{
Prapsiwi Dwi Mumpuni, Fitriyono Ayustaningwarno \\ Program Studi Ilmu Gizi Fakultas Kedokteran Universitas Diponegoro \\ Jl.Dr.Sutomo No.18, Semarang, Telp (024) 8453708, Email : gizifk@undip.ac.id
}

\begin{abstract}
Background : Tocopherol, $\gamma$-oryzanol and $\beta$-carotene are non-polar antioxidants that inhibit lipid peroxidation and prevent oxidative stress. These antioxidants found in rice bran and these levels could be effectively maintained in crude rice bran oil form. These antioxidants levels in crude rice bran oil are different according to the varieties of rice bran. Some of them are rice bran varieties from organic cultivation of mansur white rice, taun red rice and black rice from Desa Wongaya Betan, Kecamatan Penebel, Kabupaten Tabanan, Propinsi Bali.

Purpose : To know the tocopherol, $\gamma$-oryzanol and $\beta$-carotene levels and analyze the correlation with antioxidant activity of crude rice bran oil.

Method : Completely randomized design experimental with one treatments and three variation $(t=3)$ these are white, red and black crude rice bran oil with seven repetitions severally $(r=1,2,3,4,5,6,7)$ in duplicate. The independent variable is the levels of tocopherol, $\gamma$-oryzanol and $\beta$-carotene of crude rice bran oil while the dependent variable is the crude rice bran oil antioxidant activity.

Result : The extracts of crude rice bran oil that produced use $n$-Hexane solvent from $100 \mathrm{~g}$ of rice bran are 5,16\% to $6,85 \%$. The highest tocopherol, $\gamma$-oryzanol and $\beta$-carotene levels and antioxidant activity were on the white $(18.346 \pm 2.903 \mathrm{ppm})$, red $(24.201 \pm 945 \mathrm{ppm})$, black $(3,71 \pm 0,410 \mathrm{ppm})$ and red crude rice bran oil $(68,56 \pm$ $3,682 \%)$. There is a strong $\left(r_{s}=0,538\right.$ to 0,663$)$ to a very strong $\left(r_{s}=0,738\right)$ correlation between tocopherol, $\gamma$ oryzanol and $\beta$-carotene levels with antioxidant activity of crude rice bran oil.

Conclusion : The highest tocopherol, $\gamma$-oryzanol and $\beta$-carotene levels and antioxidant activity were on the white, red, black and red crude rice bran oil. There is a correlation between tocopherol, $\gamma$-oryzanol and $\beta$-carotene levels with antioxidant activity of crude rice bran oil.
\end{abstract}

Keywords : Tocopherol, $\gamma$-Oryzanol, $\beta$-Carotene, Antioxidant Activity, Crude Rice Bran Oil

\begin{abstract}
ABSTRAK
Latar Belakang : Tokoferol, $\gamma$-oryzanol dan $\beta$-karoten merupakan antioksidan non polar yang berfungsi menghambat peroksidasi lipid dan mencegah stres oksidatif. Ketiga antioksidan ini terkandung dalam bekatul dan dapat dipertahankan kadarnya secara efektif dalam bentuk minyak bekatul kasar. Kadar ketiganya dalam minyak bekatul kasar berbeda sesuai dengan varietas bekatul. Beberapa di antaranya adalah varietas bekatul hasil budidaya organik beras putih mansur, beras taun merah dan beras hitam dari Desa Wongaya Betan, Kecamatan Penebel, Kabupaten Tabanan, Propinsi Bali

Tujuan : Menganalisis kadar tokoferol, $\gamma$-oryzanol dan $\beta$-karoten serta hubungannya dengan aktivitas antioksidan minyak bekatul kasar..

Metode : Eksperimental rancangan acak lengkap dengan satu perlakuan tiga variasi $(t=3)$ yaitu minyak bekatul kasar putih, merah dan hitam, masing-masing tujuh pengulangan $(r=1,2,3,4,5,6,7)$ secara duplo. Variabel bebas adalah kadar tokoferol, $\gamma$-oryzanol dan $\beta$-karoten minyak bekatul kasar sedangkan variabel terikat adalah aktivitas antioksidan minyak bekatul kasar.

Hasil : Rendemen minyak bekatul kasar yang dihasilkan menggunakan pelarut $n$-Hexane dari $100 \mathrm{~g}$ bekatul sebesar $5,16 \%$ hingga 6,85\%. Kadar tokoferol, $\gamma$-oryzanol dan $\beta$-karoten serta aktivitas antioksidan tertinggi masingmasing terdapat pada minyak bekatul kasar putih (18.346 \pm 2.902 ppm), merah (24.200 \pm 944 ppm), hitam (3,71 \pm $0,410 \mathrm{ppm})$ dan merah $(68,66 \pm 3,682 \%)$. Terdapat hubungan yang kuat $\left(r_{s}=0,538-0,663\right)$ hingga sangat kuat $\left(r_{s}\right.$ $=0,738)$ antara kadar tokoferol, $\gamma$-oryzanol dan $\beta$-karoten dengan aktivitas antioksidan minyak bekatul kasar.

Simpulan : Kadar tokoferol, $\gamma$-oryzanol dan $\beta$-karoten serta aktivitas antioksidan tertinggi masing-masing terdapat pada minyak bekatul kasar putih, merah, hitam dan merah. Ada hubungan antara kadar tokoferol, $\gamma$-oryzanol dan $\beta$-karoten dengan aktivitas antioksidan minyak bekatul kasar.
\end{abstract}

Kata Kunci : Tokoferol, $\gamma$-Oryzanol, $\beta$-Karoten, Aktivitas Antioksidan, Minyak Bekatul Kasar

${ }^{*}$ Penulis Penanggungjawab 


\section{PENDAHULUAN}

Bekatul (rice bran) adalah bagian luar beras yang terlepas menjadi serbuk halus pada proses penggilingan padi menjadi beras yang terdiri dari lapisan aleuron, endosperm dan embrio. $^{1,2}$ Lapisan tersebut kaya komponen bioaktif pangan, beberapa di antaranya adalah tokoferol, $\gamma$-oryzanol dan $\beta$-karoten. ${ }^{3-6}$ Tokoferol, $\gamma$-oryzanol dan $\beta$-karoten merupakan golongan antioksidan non polar yang berfungsi menghambat proses peroksidasi lemak dan mencegah stres oksidatif. ${ }^{7-9}$

Tokoferol berfungsi mempertahankan integritas membran dengan cara bekerja sebagai scavenger radikal bebas oksigen, peroksida lipid dan singlet oksigen, juga melindungi minyak dan karotenoid dalam minyak dari oksidasi. ${ }^{10}$ Tokoferol relatif stabil terhadap suhu tinggi. ${ }^{11} \gamma$ oryzanol adalah bahan aktif utama dalam minyak bekatul kasar sebagai komponen antioksidan yang mampu menurunkan kadar kolesterol plasma dan mengatasi gangguan menopause. ${ }^{5}$ Aktivitas antioksidan $\gamma$-oryzanol lebih kuat dibandingkan vitamin E pada oksidasi kolesterol secara in vitro. ${ }^{8}$ $\beta$-karoten berfungsi menurunkan resiko kanker dan penyakit jantung karena kemampuan kimiawi mengikat singlet oksigen dan menghambat reaksi peroksidasi radikal. ${ }^{9}$ Radikal peroksil di dalam jaringan diikat oleh $\beta$-karoten pada tekanan oksigen yang rendah. Sifat antioksidan ini merupakan komplemen dengan tokoferol yang efektif pada tekanan oksigen tinggi. ${ }^{12}$ Hasil temuan penelitian sebelumnya, ${ }^{13}$ yang menarik adalah kandungan $\beta$-karoten tidak terdapat pada bagian beras tetapi hanya ditemukan pada bagian bekatul, terutama bekatul dari beras berpigmen. Kandungan tokoferol dan $\quad \gamma$-oryzanol lebih tinggi pada minyak bekatul kasar dibandingkan minyak nabati yang lain. ${ }^{14}$

Berdasarkan latar belakang di atas, perlu dipertimbangkan pemanfaatan tokoferol, $\gamma$ oryzanol dan $\beta$-karoten yang efektif dalam bentuk minyak bekatul kasar. Minyak bekatul kasar adalah minyak hasil ekstraksi bekatul yang telah distabilisasi dan belum mengalami proses selanjutnya pada tahap pemurnian. ${ }^{15}$ Oleh karena itu, hilangnya kandungan ketiga antioksidan tersebut dapat dihindari dan kadarnya dapat dipertahankan dengan lebih baik. ${ }^{16,17}$ Melalui bentuk minyak bekatul kasar ini diharapkan dapat diperoleh kadar antioksidan yang tinggi sehingga manfaat antioksidan tokoferol, $\gamma$-oryzanol dan $\beta$ karoten dapat digunakan secara maksimal bagi peningkatan mutu gizi pangan dan kesehatan masyarakat.

Kadar tokoferol, $\gamma$-oryzanol dan $\beta$-karoten bervariasi secara substansial sesuai dengan varietas bekatul. ${ }^{4}$ Varietas bekatul terdiri dari bekatul putih, merah dan hitam yang masingmasing dihasilkan dari beras putih dan beras yang mengandung pigmen, yaitu beras merah dan hitam. ${ }^{18}$ Beberapa di antaranya adalah varietas bekatul hasil budidaya organik beras putih mansur, beras taun merah dan beras hitam dari Desa Wongaya Betan, Kecamatan Penebel, Kabupaten Tabanan, Propinsi Bali. Penelitian ini ditujukan untuk mengetahui kadar tokoferol, $\gamma$-oryzanol dan $\beta$-karoten serta hubungannya dengan aktivitas antioksidan minyak bekatul kasar.

\section{METODE PENELITIAN}

Ruang lingkup penelitian di bidang food production yang dilakukan di Laboratorium Ilmu Pangan Program Studi Teknologi Pangan Universitas Katholik (UNIKA) Soegijapranata Semarang. Subjek penelitian ini adalah minyak bekatul kasar putih, merah dan hitam dari varietas bekatul hasil budidaya organik beras putih mansur, beras taun merah dan beras hitam dari Desa Wongaya Betan, Kecamatan Penebel, Kabupaten Tabanan, Propinsi Bali. Minyak bekatul kasar dihasilkan melalui proses ekstraksi tanpa tahap pemurnian dengan menggunakan pelarut non polar n-Hexane, sehingga diharapkan kandungan antioksidan non polar dari tiga varietas bekatul terekstrak optimal.

Penelitian ini merupakan penelitian eksperimental rancangan acak lengkap. Sebanyak satu perlakuan dengan tiga variasi $(\mathrm{t}=3)$ yaitu pada minyak bekatul kasar putih, merah dan hitam masing-masing dengan tujuh kali pengulangan $(\mathrm{r}=$ $1,2,3,4,5,6,7) .{ }^{19}$ Pengujian dilakukan secara duplo. Variabel bebas dalam penelitian ini adalah kadar tokoferol, $\gamma$-oryzanol dan $\beta$-karoten minyak bekatul kasar sedangkan variabel terikat adalah aktivitas antioksidan minyak bekatul kasar.

Prosedur penelitian dimulai dari tahap stabilisasi bekatul berdasarkan metode Damayanthi, ${ }^{20}$ dengan modifikasi yaitu dengan pemanasan basah bertekanan menggunakan otoklaf hingga suhu dan tekanan mencapai $121{ }^{\circ} \mathrm{C}$ dan $15 \mathrm{lb}$ lalu distabilkan selama 3 menit, dilanjutkan pengeringan menggunakan oven dengan suhu $110{ }^{\circ} \mathrm{C}$ selama 15 menit. Tahap kedua adalah ekstraksi minyak bekatul kasar dilakukan dengan maserasi berdasarkan metode Indrasari SD 
et $a l,{ }^{21}$ dengan modifikasi yaitu perendaman bekatul menggunakan pelarut non polar nHexane selama 24 jam dilanjutkan remaserasi dengan cara maserasi berulang terhadap ampas dari hasil maserasi selama 24 jam dengan menggunakan cara dan pelarut yang sama dimaksudkan untuk memperoleh ekstrak yang maksimal kemudian ekstrak bekatul dipisahkan dari pelarut menggunakan oven pada suhu $35{ }^{\circ} \mathrm{C}$ hingga semua pelarut teruapkan. Kadar tokoferol dianalisis dengan metode Wong et al. ${ }^{22}$ Analisis kadar $\gamma$-oryzanol menggunakan metode Gopala Krishna et al. ${ }^{23}$ Kadar $\beta$-karoten menggunakan metode Apriyantono A et al. ${ }^{24}$ Terakhir adalah aktivitas antioksidan yang dianalisis dengan metode Molyneux. ${ }^{25}$ Semua analisis menggunakan spektrofotometer Shimadzu UV Mini 1240.

Data diolah menggunakan program komputer pada derajat kepercayaan 95\% dengan terlebih dahulu dilakukan uji kenormalan data menggunakan uji statistik Shapiro-Wilk. Analisis deskriptif univariat menggunakan tabel distribusi rerata kadar tokoferol, $\gamma$-oryzanol dan $\beta$-karoten serta aktivitas antioksidan minyak bekatul kasar. Analisis bivariat hubungan antara kadar tokoferol, $\gamma$-oryzanol dan $\beta$-karoten dengan aktivitas antioksidan minyak bekatul kasar menggunakan uji korelasi non parametrik Rank Spearman.

\section{HASIL PENELITIAN \\ Ekstraksi minyak bekatul kasar}

Rendemen minyak bekatul kasar yang dihasilkan melalui proses produksi bertahap mulai dari stabilisasi hingga ekstraksi menggunakan pelarut n-Hexane masing-masing dari $100 \mathrm{~g}$ bekatul putih, merah dan hitam adalah $5,16 \%$; $6,85 \%$ dan 6,22\%.

Kadar tokoferol, $\gamma$-oryzanol dan $\beta$-karoten serta aktivitas antioksidan minyak bekatul kasar.

Tabel 1. Kadar tokoferol, $\gamma$-oryzanol dan $\beta$-karoten serta aktivitas antioksidan minyak bekatul kasar.

\begin{tabular}{lccc}
\hline \multirow{2}{*}{ Variabel } & \multicolumn{3}{c}{ Minyak bekatul kasar } \\
\cline { 2 - 4 } & Putih & Merah & Hitam \\
\hline Tokoferol $(\mathrm{ppm})$ & $18.346 \pm 2.903$ & $3.706 \pm 460$ & $5.905 \pm 1.027$ \\
$\gamma$-oryzanol $(\mathrm{ppm})$ & $13.341 \pm 863$ & $24.201 \pm 945$ & $15.007 \pm 482$ \\
$\beta$-karoten $(\mathrm{ppm})$ & $1,53 \pm 0,421$ & $2,26 \pm 0,320$ & $3,71 \pm 0,410$ \\
Aktivitas Antioksidan & $51,71 \pm 4,553$ & $68,66 \pm 3,682$ & $47,99 \pm 6,014$ \\
$(\%)$ & & \\
\hline
\end{tabular}

Kadar tokoferol, $\gamma$-oryzanol dan $\beta$-karoten serta aktivitas antioksidan tertinggi masing-masing terdapat pada minyak bekatul kasar putih $(18.346 \pm 2.902 \mathrm{ppm})$, merah $(24.200 \pm 944 \mathrm{ppm})$, hitam $(3,71 \pm 0,410 \mathrm{ppm})$ dan merah $(68,66 \pm$ $3,682 \%)$.

Hubungan antara kadar tokoferol, $\gamma$-oryzanol dan $\beta$-karoten dengan aktivitas antioksidan minyak bekatul kasar.

Tabel 2. Hubungan antara kadar tokoferol, $\gamma$-oryzanol dan $\beta$-karoten dengan aktivitas antioksidan minyak bekatul kasar.

\begin{tabular}{lccc}
\hline \multirow{2}{*}{$\begin{array}{c}\text { Antioksidan } \\
\text { non polar }\end{array}$} & \multicolumn{3}{c}{ Aktivitas Antioksidan } \\
\cline { 2 - 4 } & Putih & Merah & Hitam \\
\hline Tokoferol & $0,738^{*}$ & $0,588^{*}$ & $0,538^{*}$ \\
$\gamma$-oryzanol & $0,579^{*}$ & $0,568^{*}$ & $0,663^{*}$ \\
$\beta$-karoten & $0,540^{*}$ & $0,629^{*}$ & $0,622^{*}$ \\
\hline
\end{tabular}

* Hubungan bermakna $(\mathrm{p}<0,05)$

Ada hubungan yang bermakna antara kadar tokoferol, $\gamma$-oryzanol dan $\quad \beta$-karoten dengan aktivitas antioksidan minyak bekatul kasar. Hubungan diinterpretasikan kuat untuk nilai koefisien korelasi $\left(\mathrm{r}_{\mathrm{s}}\right)=0,50-0,69$ dan sangat kuat untuk nilai $r_{\mathrm{s}}=0,70-0,89 .{ }^{26}$ Berdasarkan nilai koefisien korelasi disimpulkan juga bahwa terdapat hubungan positif antara kadar masing-masing antioksidan non polar dengan aktivitas antioksidan minyak bekatul kasar.

\section{PEMBAHASAN}

Ekstraksi minyak bekatul kasar 
Ekstraksi dilakukan untuk mengambil komponen antioksidan non polar bekatul terutama tokoferol, $\gamma$-oryzanol dan $\beta$-karoten dalam bentuk minyak bekatul kasar menggunakan pelarut organik n-Hexane. Pelarut n-Hexane merupakan pelarut non polar yang memiliki tingkat kelarutan yang baik untuk lemak. ${ }^{27}$ Sifat fisiko-kimia $n$ Hexane tersebut diharapkan dapat menghasilkan ekstrak minyak bekatul kasar dalam jumlah maksimal. Akan tetapi, minyak bekatul kasar yang dihasilkan dalam penelitian ini dari proses ekstraksi masing-masing $100 \mathrm{~g}$ bekatul putih, merah dan hitam hanya sebesar 5,16\%; 6,85\% dan $6,22 \%$. Hasil tersebut lebih rendah dari nilai teoritis yang dinyatakan fraksi minyak dalam bekatul sebesar $15-20 \% .^{4,27}$ Hal ini selain dipengaruhi oleh jenis pelarut yang digunakan, rendemen minyak yang rendah juga dipengaruhi oleh metode stabilisasi dan ekstraksi.

Metode yang dipilih adalah stabilisasi menggunakan otoklaf dan ekstraksi menggunakan teknik maserasi. Metode yang menghasilkan rendemen lebih tinggi adalah metode stabilisasi menggunakan teknik ekstrusif dan ekstraksi menggunakan ekstraktor soxhlet. ${ }^{28}$ Stabilisasi dengan teknik ekstrusif akan dihasilkan bekatul bentuk pelet dengan ukuran partikel lebih kecil yang menyebabkan semakin besar luas permukaan kontak antara partikel dan pelarut sehingga kontak pelarut dengan partikel lebih cepat dan efektif saat proses ekstraksi. ${ }^{29}$ Ekstraksi menggunakan soxhlet dibutuhkan pemanasan dengan suhu $65-70^{\circ} \mathrm{C}$ dalam prosesnya, ${ }^{30}$ berbeda dengan maserasi. Maserasi merupakan metode ekstraksi yang dilakukan pada suhu ruang. ${ }^{31}$ Semakin tinggi suhu ekstraksi, laju pelarutan zat terlarut oleh pelarut semakin tinggi dan laju difusi pelarut ke dalam serta ke luar padatan juga semakin tinggi, ${ }^{29}$ sehingga diperoleh rendemen yang lebih tinggi pula. Rendemen hasil maserasi yang lebih rendah juga dipengaruhi oleh prinsip kerja perbedaan konsentrasi yang terjadi pada saat perendaman bekatul. Oleh karena itu, dilakukan remaserasi yang bertujuan untuk mengatasi kelemahan metode ini agar dapat diperoleh rendemen lebih tinggi. $^{32}$ Hasil rendemen yang dihasilkan tetap tidak maksimal walaupun telah dilakukan remaserasi. Meskipun demikian, penggunaan otoklaf dan maserasi memiliki kelebihan dalam mencegah rusaknya kandungan antioksidan non polar yang diteliti sehingga diharapkan kadar tokoferol, $\gamma$-oryzanol dan $\beta$-karoten minyak bekatul kasar dapat diekstraksi dalam kadar maksimal dengan kualitas yang baik. Selain itu, kedua metode tersebut juga lebih sederhana, mudah dan murah untuk diterapkan secara komersial. ${ }^{20}$

Kadar tokoferol, $\gamma$-oryzanol dan $\beta$-karoten serta aktivitas antioksidan minyak bekatul kasar

Kadar tokoferol tertinggi terdapat pada minyak bekatul putih sebesar $18.346 \pm 2.903 \mathrm{ppm}$. Hasil ini didukung penelitian terdahulu, ${ }^{33}$ kadar tokoferol tertinggi terdapat pada bekatul beras putih. Kadar tokoferol ketiga minyak bekatul kasar tersebut jauh lebih tinggi dibandingkan hasil penelitian sebelumnya, ${ }^{34}$ yang menggunakan proses pemurnian yaitu sebesar $2.647 \mathrm{ppm}$. Hal ini disebabkan proses pemurnian bertujuan untuk menghilangkan zat-zat yang dianggap sebagai zat pengotor dalam minyak, antara lain asam lemak bebas, lilin, fraksi tidak tersabunkan, fosfolipid, glikolipid dan pigmen. ${ }^{15,35}$ Tokoferol, $\gamma$-oryzanol dan $\quad \beta$-karoten termasuk dalam fraksi tidak tersabunkan dari komponen non trigliserida minyak bekatul kasar artinya di saat yang sama pemurnian juga merusak sebagian besar kandungan tokoferol, $\gamma$-oryzanol dan $\beta$ karoten. ${ }^{17,27}$ Hal ini juga dapat dilihat dari kadar tokoferol dalam minyak makan bekatul yang sebagian besar telah melewati tahap pemurnian yaitu sebesar $81 \mathrm{ppm}^{2}$ Begitu pula dengan kadar $\gamma$ oryzanol pada minyak makan bekatul sebesar 3.000 ppm. ${ }^{36,37}$ Minyak bekatul kasar merupakan bentuk minyak bekatul yang belum dimurnikan sehingga hilangnya sebagian besar kandungan tokoferol, $\gamma$-oryzanol dan $\beta$-karoten dapat dihindari dan kadarnya dapat dipertahankan dengan lebih baik. $^{16,17}$

Kadar $\gamma$-oryzanol minyak bekatul kasar merah $(24.201 \pm 945 \mathrm{ppm})$ tertinggi di antara semua sampel, lebih tinggi dari kisaran kadar $\gamma$ oryzanol dalam minyak bekatul kasar menurut Codex Standar, ${ }^{38}$ dengan pelarut $\mathrm{n}$-Heptan yaitu antara $9.000-21.000$ ppm. Pelarut n-Heptan juga merupakan pelarut non polar, tetapi memiliki titik didih yang cukup tinggi yaitu sebesar $98{ }^{\circ} \mathrm{C}^{39}$ Pelarut n-Hexane yang digunakan memiliki titik didih yang rendah yaitu sekitar 67-70 ${ }^{\circ} \mathrm{C},{ }^{27}$ sehingga tidak merusak senyawa antioksidan. Kadar $\gamma$-oryzanol hasil penelitian ini juga lebih tinggi dibandingkan penelitian lain, ${ }^{23}$ yang menggunakan soxhlet pada proses ekstrasinya yaitu sebesar $17.800 \mathrm{ppm}$. Ekstraksi menggunakan soxhlet dibutuhkan pemanasan dengan suhu 65-70 ${ }^{\circ} \mathrm{C} .{ }^{30}$ Maserasi merupakan metode ekstraksi yang dilakukan pada suhu ruang. ${ }^{31}$ Metode maserasi 
yang menggunakan suhu ekstraksi di bawah titik didih pelarut dapat mencegah terdegradasinya komponen termolabil bekatul akibat panas. ${ }^{40}$ Kadar $\gamma$-oryzanol sangat tinggi pada ketiga jenis minyak bekatul kasar karena $\gamma$-oryzanol adalah bahan aktif mayoritas dalam minyak bekatul kasar. ${ }^{5}$ Kadar $\gamma$-oryzanol dapat mencapai sepuluh kali kadar vitamin E. $^{41}$

Berbeda dengan kadar tokoferol dan $\gamma$ oryzanol, kadar $\beta$-karoten berurutan dari minyak bekatul kasar putih $(1,53 \pm 0,421 \mathrm{ppm})$, merah $(2,26 \pm 0,320 \mathrm{ppm})$ kemudian hitam $(3,71 \pm 0,410$ ppm). Hal ini didukung juga oleh hasil penelitian terdahulu, $^{13}$ yang menggunakan pelarut diklorometana dan isopropanol yaitu kadar $\beta$ karoten tertinggi terdapat pada beras hitam sebesar $0,13 \mathrm{ppm}$, lebih sedikit dalam beras merah dan dalam jumlah yang sangat kecil dalam beras putih. Kadar $\beta$-karoten pada beras tersebut lebih rendah dari kadar $\beta$-karoten minyak bekatul kasar pada penelitian ini. Hal ini mungkin disebabkan oleh penggunaan pelarut diklorometana dan isopropanol. Diklorometana dan isopropanol merupakan pelarut polar, ${ }^{39}$ sedangkan $\mathrm{n}$-Hexane adalah pelarut non polar dengan tingkat kelarutan yang baik untuk lemak, ${ }^{27}$ selain itu tingkat kepolaran n-Hexane paling mendekati kepolaran tokoferol, $\gamma$-oryzanol dan $\beta$-karoten ${ }^{33}$ sehingga diperoleh kadar $\beta$-karoten yang lebih tinggi. Hasil ini sekaligus membenarkan kesimpulan penelitian sebelumnya, ${ }^{13}$ bahwa kandungan karotenoid tidak terdapat pada bagian beras melainkan hanya ditemukan pada bagian bekatul, terutama bekatul dari beras berpigmen.

Aktivitas antioksidan tertinggi $(68,66 \pm$ $3,682 \%)$ terdapat pada minyak bekatul kasar merah diikuti oleh putih $(51,71 \pm 4,553 \%)$ dan hitam $(47,99 \pm 6,014 \%)$. Hasil ini berbeda dengan penelitian sebelumnya, ${ }^{33}$ aktivitas reduksi radikal bebas tertinggi ekstrak bekatul dengan pelarut methanol ditemukan pada ekstrak bekatul hitam, kemudian merah dan yang terendah adalah pada ekstrak bekatul putih. Hal ini salah satunya disebabkan oleh penggunaan pelarut yang berbeda, yaitu methanol. Methanol merupakan pelarut polar. ${ }^{39}$ Perbedaan aktivitas antioksidan juga dapat disebabkan oleh beberapa faktor lain yaitu kadar yang secara substansial bervariasi sesuai varietas bekatul. ${ }^{4}$ Selain itu adalah struktur antioksidan serta kondisi reaksi. ${ }^{42}$

Hubungan antara kadar tokoferol, $\gamma$-oryzanol dan $\beta$-karoten dengan aktivitas antioksidan minyak bekatul kasar.
Hubungan yang bermakna antara kadar tokoferol, $\gamma$-oryzanol dan $\quad \beta$-karoten dengan aktivitas antioksidan minyak bekatul kasar putih, merah dan hitam dapat diinterpretasikan kuat $\left(\mathrm{r}_{\mathrm{s}}=\right.$ $0,538-0,663)$ hingga sangat kuat $\quad\left(\mathrm{r}_{\mathrm{s}}=\right.$ 0,738 ) dengan arah hubungan yang positif. ${ }^{26} \mathrm{Hal}$ ini menunjukkan bahwa semakin tinggi kadar tokoferol, $\gamma$-oryzanol dan $\beta$-karoten, maka aktivitas antioksidan pada masing-masing minyak bekatul kasar semakin besar. Hasil tersebut sesuai dengan penelitian sebelumnya, ${ }^{42}$ semakin tinggi kadar antioksidan maka semakin tinggi laju penghambatan peroksidasi lipid oleh radikal bebas dalam minyak bekatul kasar.

Aktivitas antioksidan minyak bekatul kasar putih dipengaruhi paling tinggi oleh kadar tokoferol $\left(r_{\mathrm{s}}=0,738\right)$, kemudian $\gamma$-oryzanol $\left(\mathrm{r}_{\mathrm{s}}=\right.$ $0,579)$ dan $\beta$-karoten $\left(\mathrm{r}_{\mathrm{s}}=0,540\right)$. Kekuatan hubungan kadar tokoferol dengan aktivitas antioksidan minyak bekatul kasar putih lebih besar dibandingkan dengan $\gamma$-oryzanol dan $\beta$ karoten. Hal ini disebabkan oleh kadar tokoferol $(18.346 \pm 2.903 \mathrm{ppm})$ yang lebih tinggi dibandingkan kadar $\gamma$-oryzanol (13.341 \pm 863 ppm) dan $\beta$-karoten $(1,53 \pm 0,421 \mathrm{ppm})$. Nilai $\mathrm{r}_{\mathrm{s}}$ ketiganya menunjukkan semakin tinggi kadar senyawa antioksidan maka akan memiliki kekuatan hubungan yang lebih besar terhadap aktivitas antioksidan dalam minyak bekatul kasar putih. Hal yang sama terjadi pada kadar $\gamma$-oryzanol minyak bekatul kasar hitam. Kadar $\gamma$-oryzanol yang lebih tinggi (15.007 $\pm 482 \mathrm{ppm})$ dibandingkan tokoferol $(5.905 \pm 1.027 \mathrm{ppm})$ dan $\beta$-karoten $(3,71 \pm 0,410 \mathrm{ppm})$ menunjukkan kekuatan hubungan dengan aktivitas antioksidan yang lebih tinggi $\left(r_{s}=0,663\right)$ dibandingkan tokoferol $\left(\mathrm{r}_{\mathrm{s}}=0,538\right)$ dan $\beta$-karoten $\left(\mathrm{r}_{\mathrm{s}}=0,622\right)$. Akan tetapi, sebaliknya yang terjadi pada tokoferol dan $\beta$-karoten. Kadar $\beta$-karoten yang lebih rendah dibandingkan tokoferol justru menunjukkan kekuatan hubungan dengan aktivitas antioksidan minyak bekatul kasar hitam yang lebih tinggi. Begitu pula yang terjadi pada hubungan kadar tokoferol, $\gamma$-oryzanol dan $\beta$-karoten dengan aktivitas antioksidan minyak bekatul kasar merah. Kadar antioksidan tertinggi adalah $\gamma$-oryzanol $(24.201 \pm 945 \mathrm{ppm})$ diikuti oleh tokoferol (3.706 \pm $460 \mathrm{ppm})$ dan $\beta$-karoten $(2,26 \pm 0,320 \mathrm{ppm})$. Akan tetapi kekuatan hubungan tertinggi terdapat pada $\beta$-karoten $\left(\mathrm{r}_{\mathrm{s}}=0,629\right)$, kemudian tokoferol $\left(\mathrm{r}_{\mathrm{s}}=\right.$ $0,588)$ dan $\gamma$-oryzanol $\left(r_{s}=0,568\right)$.

Hal ini menunjukkan bahwa aktivitas antioksidan tidak hanya dipengaruhi oleh kadar 
antioksidan tetapi juga faktor yang lain. Beberapa faktor yang mungkin mempengaruhi aktivitas antioksidan minyak bekatul kasar dalam penelitian ini adalah kondisi reaksi dan struktur antioksidan. ${ }^{42}$ Tokoferol dan $\gamma$-oryzanol termasuk dalam antioksidan primer dan $\beta$-karoten termasuk antioksidan sekunder. Antioksidan primer dan sekunder bersifat sinergis, ${ }^{42}$ satu sama lain bertindak sebagai komplemen dan saling memperkuat sifat antioksidan yang akan mempengaruhi kondisi reaksi saat dilakukan pengukuran aktivitas antioksidan. Oleh karena itu, akan memberikan hasil yang tidak selalu sama pada kekuatan hubungan antara kadar tokoferol, $\gamma$ oryzanol dan $\beta$-karoten dengan aktivitas antioksidan minyak bekatul kasar.

Aktivitas antioksidan juga dipengaruhi oleh faktor struktur antioksidan, dapat dilihat pada pengaruh kadar tokoferol terhadap aktivitas antioksidan minyak bekatul kasar merah yang lebih kuat dibandingkan $\gamma$-oryzanol walaupun kadar tokoferol lebih rendah. Hal ini disebabkan bekatul mengandung beberapa jenis antioksidan dengan proporsi yang bervariasi. ${ }^{43}$ Antioksidan non polar minyak bekatul kasar tidak hanya tokoferol, $\gamma$-oryzanol dan $\beta$-karoten, tetapi juga tokotrienol, ${ }^{4}$ yang tidak dianalisis pada penelitian ini. Kadar tokotrienol yang mungkin lebih tinggi dapat mempengaruhi kondisi reaksi tokoferol dengan radikal bebas DPPH. Dapat dijelaskan seperti ini karena struktur kimia tokotrienol sama dengan tokoferol, hanya berbeda pada rantai sampingnya, tokoferol memiliki rantai samping phytyl yang jenuh sedangkan tokotrienol memiliki rantai samping isoprenoid yang tidak jenuh. ${ }^{44}$ Kadar tokotrienol pada minyak makan bekatul (336 ppm) lebih tinggi dibandingkan tokoferol (81 $\mathrm{ppm}){ }^{2}$ Aktivitas antioksidan tokotrienol juga terbukti lebih kuat dibandingkan tokoferol. ${ }^{45}$ Faktor inilah yang mungkin berpengaruh terhadap kekuatan hubungan antara kadar tokoferol dengan aktivitas antioksidan minyak bekatul kasar merah.

Aktivitas antioksidan minyak bekatul kasar dalam penelitian ini tidak hanya dipengaruhi oleh kadar tokoferol, $\gamma$-oryzanol dan $\beta$-karoten. Akan tetapi, masing-masing senyawa antioksidan non polar tersebut dihasilkan dalam kadar yang tinggi. Oleh karena itu, minyak bekatul kasar dari varietas bekatul dalam penelitian ini merupakan bentuk yang patut dipertimbangkan untuk pemanfaatan tokoferol, $\gamma$-oryzanol dan $\beta$-karoten secara efektif. Ketiganya dapat digunakan sebagai bahan baku fungsional pangan maupun farmasi sehingga dapat dimanfaatkan secara maksimal bagi peningkatan mutu gizi pangan dan kesehatan masyarakat.

\section{SIMPULAN}

Kadar tokoferol, $\gamma$-oryzanol dan $\beta$-karoten serta aktivitas antioksidan tertinggi masing-masing terdapat pada minyak bekatul kasar putih, merah, hitam dan merah. Ada hubungan antara kadar tokoferol, $\gamma$-oryzanol dan $\beta$-karoten dengan aktivitas antioksidan minyak bekatul kasar.

\section{SARAN}

1. Penelitian lebih lanjut perlu dilakukan untuk mengetahui jenis antioksidan non polar lain yang ikut berpengaruh terhadap aktivitas antioksidan minyak bekatul kasar.

2. Pengolahan lanjutan bekatul yang lebih baik secara kimiawi diperlukan untuk menghasilkan minyak bekatul tanpa menghilangkan kandungan antioksidan non polar yang terkandung di dalamnya.

\section{UCAPAN TERIMA KASIH}

Ucapan terima kasih saya sampaikan kepada Program Studi Ilmu Gizi, Fakultas Kedokteran Universitas Diponegoro Semarang yang telah memberikan bantuan untuk alokasi dana penelitian ini.

\section{DAFTAR PUSTAKA}

1. Ardiansyah. Stabilisasi dan sifat fungsional bekatul. B'tul : Tepung bekatul stabil, murni, lembut dan menyehatkan. [Online] 2010 [diakses 5 Mei 2011] dari: http://www.bekatul.net/bekatulkesehatan/stabilisasidansifatfungsional bekatul

2. Hadipernata M. Mengolah dedak menjadi minyak (rice bran oil). Warta Penelitian dan Pengembangan Pertanian. Bogor: Balai Besar Penelitian dan Pengembangan Pascapanen Pertanian; 2007; 29(4):8-10.

3. Ardiansyah. Potensi dan karakteristik rice bran oil. Food Review Indonesia. [Online] 2008 [diakses 1 Oktober 2011] dari: http://www.foodreview.biz/ login/preview.php?view\&id=56042

4. Zigoneanu IG. Alpha-tocopherol: Extraction from rice bran by microwave-assisted method and entrapment and release from polymeric nanoparticles [thesis]. Romania: Babes-Bolyai University; 2006.

5. Boonsit P, Karladee D, Phongpiachan P. Gamma oryzanol content in purple rice thailand local genotypes. Thailand: Faculty of Agriculture, Chiang Mai University. Deutscher Tropentag; 2006. 
6. Chanphrom P. Antioxidants and antioxidant activities of pigmented rice varieties and rice bran [thesis]. Mahidol University; 2007.

7. Ardiansyah. Antikanker bahan aktif dari bekatul. B’tul: Tepung Bekatul Stabil, Murni, Lembut dan Menyehatkan. [Online] 2010 [diakses 5 Mei 2011] dari: $\quad$ http://www.bekatul.net/bekatulkesehatan/antikankerbahanaktifdari bekatul

8. Damayanthi E, Muchtadi D, Zakaria FR, Syarief $H$, Wijaya CH, Damardjati DS. Aktivitas antioksidan minyak bekatul padi awet dan fraksinya secara in vitro. Jurnal Teknol dan Industri Pangan 2004; XV(1):11-8.

9. Hathcock JN. Vitamin and mineral safety. $2^{\text {nd }}$. ed. Council for Responsible Nutrition (CRN); 2004.

10. Winarsi H. Antioksidan alami dan radikal bebas. Yogyakarta: Kanisius; 2007.

11. Winarno FG. Kimia pangan dan gizi. Jakarta: PT. Gramedia Pustaka Utama; 2002.

12. Lautan J. Radikal bebas pada eritrosit dan leukosit. Cermin Dunia Kedokteran 1997; (116).

13. Frei M, Becker K. Agro-biodiversity in subsistence-oriented farming systems in a Philippine upland region: nutritional considerations. Biodiversity and Conservation 2004; 13: 1591-610.

14. California Rice Oil Company. Compare the health benefits of rice bran oil to other cooking oils. California Rice Oil Company. [Online] 2001 [diakses 5September 2011] dari: http://www.californiariceoil.com/nutrition.html

15. Orthoefer FT. Rice bran oil. Di dalam: Shahidi F, editor. Bailey's Industrial Oil And Fat Products Edisi ke-6, Volume ke-2, Edible Oil and Fat Product: Edible Oil. Hoboken: John Wiley \& Sons, Inc; 2005.

16. RITO Partnership. Why rice bran oil. RITO partnership: Rice Bran Oil Info. [Online] 2008 [diakses 9 Agustus 2011] dari: http://www. ricebranoil.info/why/ index.html

17. Zullaikah S, Melwita $\mathrm{E}, \mathrm{Ju} \mathrm{YH}$. Isolation of oryzanol from crude rice bran oil. Bioresource Technology 2009; 100:299-302.

18. Ling WH, Cheng QX, Ma J, Wang T. Red and black rice decrease atherosclerotic plaque formation and increase antioxidant status in rabbits. J Nutr 2001; 131:1421-6.

19. Gomez, K. A. dan Gomez, A.A. Prosedur statistik untuk penelitian pertanian. Ed-2. Diterjemahkan oleh: Sjamsudin, E dan Baharsjah, J.S. Jakarta: UI Press; 1995.

20. Damayanthi E. Rice bran stabilization and $\gamma$ oryzanol content of two local paddy varieties "IR 64" and "Cisadane Muncul". Jurnal Teknol dan Industri Pangan 2001; XII(1):72-4.

21. Indrasari SD, Koswara S, Muchtadi D, Nagara LM. The effect of heating on the physochemical characteristic of rice brand oil. Indonesian Journal of Agriculture Science 2001; 2(1):1-5.
22. Wong ML, Tims RE, Goh EM. Colorimetric determination of total tocopherols in palm oil, olein and stearin. J Am Oil Chem 1988; 65(2).

23. Gopala Krishna AG, Hemakumar KH, Khatoon S. Study on the composition of rice bran oil and its higher free fatty acids value. J Amer Oil Chem Soc 2006; 83:117-20.

24. Apriyantono A et al. Petunjuk laboratorium analisis pangan. Bogor: IPB Press; 1989.

25. Molyneux P. The use of the stable free radical diphenylpicrylhydrazyl (DPPH) for estimating antioxidant activity. J Sci Technol 2004; 26(2):2119.

26. De Vaus, David. Survey in Social Research. $5^{\text {th }}$ Edition. New South Wales: Allen and Unwin; 2002 .p. 259.

27. Tangprawat C. Determination of total lipid content and gamma-oryzanol in rice bran [thesis]. Mahidol University; 2006.

28. Putrawan IDGA, Mariyana R, Rosmawati I. Ekstraksi minyak dedak padi menggunakan isopropil alkohol. Disampaikan pada Seminar Nasional Teknik Kimia Indonesia; 2009 Okt 19-20; Bandung, Indonesia.

29. Nasir S, Fitriyanti, Kamila H. Ekstraksi dedak padi menjadi minyak mentah dedak padi (crude rice bran oil) dengan menggunakan pelarut n-hexane dan ethanol. Jurnal Rekayasa Sriwijaya 2009; 18(1):37-44.

30. Imsanguan $\mathrm{P}$, Roaysubtawee A, Borirak R, Pongamphai S, Douglas S, Douglas PL. Extraction of tocopherol and oryzanol from rice bran. LWT Food Science and Technology. 31 Aug 2007.

31. Ditjen POM. Metode Analisis PPOM. Jakarta: Departemen Kesehatan RI; 2000

32. Digunawan. Cara Mengekstraksi Tanaman dengan Metode Maserasi. [Online] 2011 [diakses 20 September 2011] dari: http://id.scribd.com/doc/77341671/EkstraksiTanaman-Dengan-Maserasi-Perkolasi-Soxhlet

33. Laokuldilok T, Shoemaker CF, Jongkaewwattana $\mathrm{S}$, Tulyathan V. Antioxidants and antioxidant activity of several pigmented rice brans. J Agric Food Chem 2011; 59:193-9.

34. Damayanthi E. Karakteristik bekatul padi (Oryza sativa) awet serta aktivitas antioksidan dan penghambatan proliferasi sel kanker secara in vitro dari minyak dan fraksinya [tesis]. Institut Pertanian Bogor; 2002.

35. Aryusuk K, Puengtham J, Lilitchan S, Jevashoke N, Krisnangkura K. Effects of crude rice bran oil components on alkali-refining loss. J Amer Oil Chem Soc 2008; 85(5):475-9.

36. Chamnarnsin P, Ahromrit A. Effect of heating on gamma-oryzanol content and degree of gelatinization of Thai coloured rice. Proceeding of the $12^{\text {th }}$ ASEAN Food Conference; 2011 Jun 16-18; BITEC Bagna, Bangkok, Thailand. Thailand: 
Department of Food Technology, Khon Kaen University; 2011.

37. Beverly Clevidence. Rice Phytonutrients: Do Realistic Intake of Rice and RBO Promote Health? [Online] 2011 [diakses 26 September 2011] dari: http://www.usarice.com/doclib/124/3837.pdf.

38. FAO/WHO Food Standard [Codex Alimentarius]. CODEX STAN 210-1999: Named Vegetable Oil 2009 Rev. 3. [Online] 2009 [diakses 26 September 2011] dari: http://www.codexalimentarius.net/download/standa rds/336/CXS_210e.pdf

39. Morrison RT, Boyd RN. Organic Chemistry. $6^{\text {th }}$ edition. New Jersey: Prentice Hall; 1992.

40. Sheehan J, Dunahay TG, Benemann JR, Roessler PG, Weissman JC. A look back at the U.S. Department of energy's aquatic species programbiodiesel from algae. Colorado: Midwest Research Institute; 1998. Contract No.:DE-AC3683CH10093. Sponsored by National Renewable Energy Laboratory.

41. Xu Z, Hua N, Godber JS. Antioxidant activity of tocopherols, tocotrienols and $\gamma$-oryzanol components from rice bran against choles-terol oxidation accelerated by 2,2'-azobis (2methylpropionamidine) dihydrocholoride. J. Agric. Food Chem. 2001; 49: 2077-81.

42. Gordon $\mathrm{MH}$. The mechanism of antioxidants action in vitro. Di dalam: Hudson BJF, editor. Food Antioxidant. London: Elsevier Applied Science. 1990. p. 1-18.

43. Prior RL, Hoang H, Gu L, Wu X, Bacchiocca M, Howard L, et al. Assays for hydrophilic and lipophilic antioxidant capacity (oxygen radical absorbance capacity (ORACFL)) of plasma and other biological and food samples. Journal of Agricultural and Food Chemistry 2003; 51: 3273 279.

44. Theriault A, Chao TC and Gapor A. Atherosclerosis; 2002. 160. p. 21-30.

45. Aggarwal B, Sundaram C, Prasad S and Kannapan R. Tocotrienols, the vitamin $\mathrm{E}$ of the $21^{\text {st }}$ century: Its potential against cancer and other chronic diseases. Biochemical Pharmacology 2010; 80: 1613-631. 